\title{
Bazı orman ağacı ve çalı türleri tohumlarının çimlendirilmesinde vermikompost ürünlerinin etkileri
}

\section{The effects of vermicompost products on the germination of the seeds of some forest trees and shrubs}

\author{
Mehmet SEZGiN, Elif ŞIMŞEK
}

Çankırı Karatekin Üniversitesi Fen Fakültesi Biyoloji Bölümü, Çankırı, Türkiye

\section{Eser Bilgisi / Article Info}

Araştırma makalesi / Research article

DOI: $10.17474 /$ artvinofd.282604

Sorumlu yazar / Corresponding author

Mehmet SEZGiN

e-mail: sezgin@karatekin.edu.tr

Geliş tarihi / Received

30.12.2016

Düzeltme tarihi / Received in revised form

13.02.2017

Elektronik erişim / Online available

03.03.2017

\section{Anahtar kelimeler: \\ Çimlenme \\ Çimlenme engel \\ Vermikültür \\ Vermikompost}

\section{Keywords:}

Germination

Germination inhibition

Vermiculture

Vermicompost

\begin{abstract}
Özet
Çimlenme engelini aşmak için tohumların çeşitli ön işlemlerden geçirilmeleri zorunludur. Bu ön işlemlerin yanı sıra çimlenme engeli in vitro koşullar altında da giderilebilmektedir. Çalışmada, Robinia pseudoacacia L., Pinus nigra J. F. Arnold, Pinus sylvestris L., Acer negundo L., Capparis spinosa L. ve Lycium europaeum L. bitkilerinin tohumları çimlenme engelini gidermek için çeşitli yoğunluktaki vermikompost çayları ile muamele edilmiştir. Dört hafta süre ile inkübe edilen tohumlarda, vermikompost yoğunluklarına bağlı olarak tohumların, vermikompost ortamında olmayanlara oranla daha iyi bir çimlenme gösterdikleri gözlenmiştir. Çimlenmeyi olumlu yönde etkileyen vermikompost ve ürünlerinin fidanlık çalışmalarında kullanılabilecek hem pratik hem de faydalı bir ürün olduğu ortaya konulmuştur.
\end{abstract}

\begin{abstract}
It is necessary to pre-treat the seeds in order to overcome the germination inhibition. In addition to this pre-treatment, germination inhibition should be overcome in vitro conditions. In this study, the seeds of Robinia pseudoacacia L, Pinus nigra J.F Arnold, Pinus sylvestris L, Acer negundo L, Capparis sipinosa $L$ and $L y c i u m$ europaeum $L$ were treated with various concentrations of vermicompost tea for germination. It was observed that the seeds incubated for four weeks had better germination than those not in the vermicompost environment. Vermicompost and its products, which affect germination positively, have been proved to be both practical and useful product that can be used in nursery studies.
\end{abstract}

\section{GiRiş}

Çimlenme, tohum zarının yarılması ve yeni bitkinin ortaya çıkmasıyla kendini gösteren embriyo büyümesinin yeniden başlaması safhasıdır. Çimlenme, tohum zarı veya tohum kabuğu tarafından su alınması ile başlar. Böylece iç dokular hidratlanır ve tohum zarının yarılmasına neden olan embriyo büyümesini uyaran enzimler aktif hale gelir (Yacubson 1993). Çimlenme esnasında tohumda mekanik, kimyasal ve morfolojik bazı değişimler olmaktadır. Mekanik değişiklik tohumun su alarak şişmesiyle başlamaktadır. Bu su alımının süresi sıcaklık kadar, bitki türüne, tohumun kabuk sertliğine ve geçirgenliğine bağııdır (Beck 2011). Çimlenme olabilmesi için; tohumun çimlenme yeteneğinde olması, uygun çevre koşulları (su, sıcaklık, oksijen vs.) bulunması ve tohumun herhangi bir çimlenme engeli olmaması veya bu engeli aşmış olması gerekmektedir. Tohumun çimlenmesi için gerekli şartlar sağlandığı halde tohumun çimlenmesinin engellenmesi çimlenme engeli olarak tanımlanır (Yacubson 1993; Beck 2011). Bu çimlenme engelleri tohumun kabuk yapısından, embriyodan ve endospermden kaynaklanabilir. Bu engellerin aşılması için tohumun çeşitli işlemlerden geçirilmesi gerekir. Çimlenme engelini gidermek için yapılan işlemlere, tohumun ekim öncesi göreceği işlemler, ön işlem veya uyarıcı işlem denilmektedir. Asitle muamele, tohum kabuğunu aşındırılması, sıcak suda bırakma, sıcak katlama, soğuk katlama gibi teknikler kullanılarak çimlenme engeli aşılır (Anşin ve Özkan 1997; Ürgenç 1998; Beck 2011; Gültekin 2014). Tüm bu yöntemlerin haricinde in vitro tekniklerden biri olan embriyo kültürü yardımıyla, mineral tuz ve şeker içeren basit bitki besin ortamları içerisinde farklı birçok bitkinin embriyoları çimlendirilebilmektedir (Bürün ve Gürel 2002).

Ziraat ve ormancılık alanlarında yapılan çalışmalarda insan sağlığını ve çevre güvenliğini riske atan, toprak 
kalitesini düşüren, patojen dayanıklııı̆ını arttıran yoğun agro-kimyasal kullanımı, doğal kaynakların güvenliği konusunda oldukça ciddi endişelere sebep olmuştur. Tüm bunlar, bilim adamlarını ve karar vericileri, biyolojik gübre ve organik ürünler kullanımını hedefleyen sürdürülebilir tarımsal üretim sistemlerinin geliştirilmesine yöneltmiştir. Bu alanda, her bakımdan toprak kalitesini arttıran aerobik kompost ve vermikompost ürünleri çok büyük önem kazanmıştır (Şimşek 2007; Gürpınar 2008). ilk olarak 1950 'li yıllarda ortaya çıkan vermikültür kavramı; kültürel ortamda toprak solucanlarının çoğaltılabilmesi, yetiştirilmesi ve bunlarla ilgili bir takım yan faaliyetlerin yürütülmesidir (Saday 2013). Genel olarak her türlü organik atık veya atıkların solucanlara uygun bir kompozisyon içinde besin olarak sunulması ile elde edilen solucan gübresine vermikompost veya vermikest denilmektedir (Scheurell ve Mahaffee 2002; Şimşek-Erşahin vd. 2009; Şimşek-Erşahin 2010; Patangray 2014). Doube ve Brown (1998) bu dışkı materyalinin; granülümsü ama homojen, kokusuz ve mikrobiyolojik açıdan solucanın beslendiği materyalden daha aktif olduğu belirtmektedir. Buchanan vd. (1988) solucan dışkısı içindeki önemli bitki besin elementlerinin suda çözünürlüklerinin, solucanın besin olarak içine aldığı materyalin çözünürlüğünden daha fazla olduğunu ve düşük hızla bu besinleri ortama bıraktıklarından daha uzun süre bitkiyi besleyebildiklerini ifade etmektedir. Bununla birlikte, vermikompostun mikrobiyal aktivite seviyesi topraktan 10 ila 20 kat daha fazladır. Bu yüksek mikrobiyal çeşitliliğin, bitki gelişimini teşvik eden kimyasalların ve zararlı bitki patojenlerinin gelişimini baskılayan enzim ve çeşitli bileşiklerin üretilmesini sağladığı bilinmektedir (Logsdon 1994). Vermikompostun içerdiği solucan mukusu ile çevrelenmiş besin elementleri yavaş salııı ve bitki tarafından hemen kullanılabilecek formdadır. Ayrıca, vermikompostun gözenekli yapısı, yüksek havalanma ve su tutma kapasitesi, bu maddeyi mükemmel bir toprak düzenleyicisi yapmasının yanı sıra bitki köklerini aşırı sıcaklıklardan korur, erozyonu ve yabancı ot gelişimini azaltır (Şimşek 2007). Kısacası, vermikültür süreci sonunda elde edilen solucan gübresinin, ekolojik, ekonomik ve tarımsal anlamda birçok faydası vardır (Türkmen 2016).
Çalışmada; vermikompostun, bazı tohumların çimlenmeleri üzerine olan etkilerinin belirlenmesi ile fidanlık çalışmalarında kullanılabilecek pratik bir yöntemin geliştirilebilmesi amaçlanmıştır. Yarı kurak bölge ağaçlandırma çalışmalarında kullanılan ve önemli orman ağacı türlerimizden olan Robinia pseudoacacia L., Pinus nigra J.F. Arnold, Pinus sylvestris L., Acer negundo L. ve çalı formundaki Capparis spinosa L. ile Lycium europaeum L. tohumları çalışmaya konu edilmiştir. Bu türler ekonomik açıdan oldukça kıymetlidir ve tohumlarının çimlenme kabiliyetleri oldukça düşüktür.

\section{MATERYAL ve YÖNTEM}

Çalışmada materyal olarak R. pseudoacacia L., P. nigra J. F. Arnold., P. sylvestris L., $A$. negundo L. ve çalı formundaki $C$. spinosa $L$. ile $L$. europaeum $L$. tohumları kullanılmışır. Tohumlar, yarı kurak bölgede yer alan, Çankırı ili ve çevresinin ağaçlandırılmasında fidan temin eden Kenbağ Orman Fidanlığı'ndan alınmıştır.

Vermikompost 1:5 oranında çeşme suyu ile sulandırılıp, oda sıcaklığında bir hafta bekletilmiştir (Şekil 1). Daha sonra sulandırılan vermikompost filtre kâğıdı yardımıyla süzülerek ve vermikompost sıvısı (çayı) elde edilmiştir.

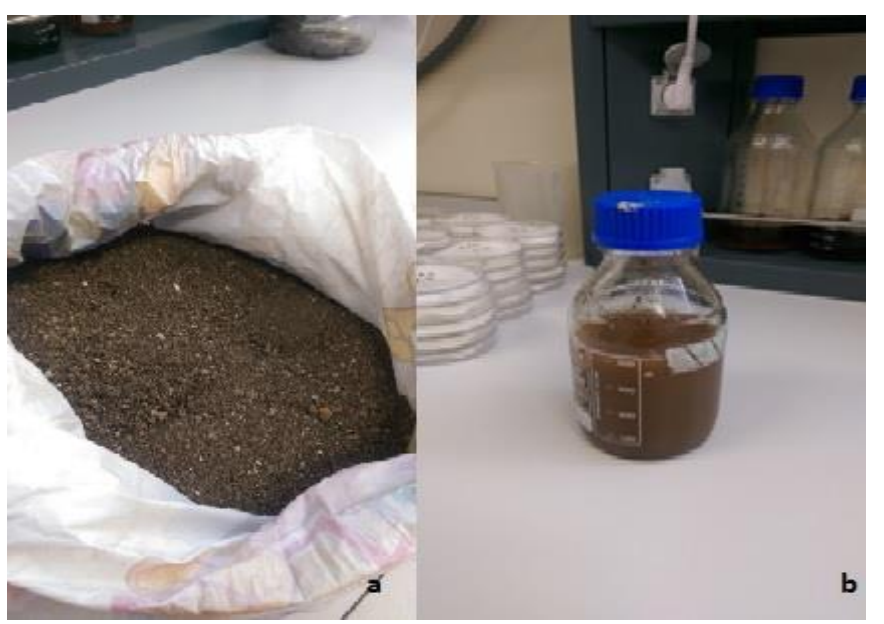

Şekil 1. Vermikompost ürünleri a) Solucan gübresi, b) Vermikompost çayı

\section{Süzüntünün tohumlara uygulanması}

Vermikomposttan elde edilen konsantre sIVI, doğrudan 1:1,1:2 ve 1:4 oranında çeşme suyu ile sulandırılarak daha seyreltik hale getirilmiştir (Scheurell ve Mahaffee 2002). Kontrol grubu ile birlikte toplam 4 farklı dozda uygulama yapılmıştır (Şekil 2). Tohumların çimlendirilmesi $90 \mathrm{~mm}$ 
çapındaki steril petri kutularında çift katlı filtre kâğıdı kullanılarak gerçekleştirilmiştir. Her bir tür için, 4 farklı uygulama ve her bir petri kutusuna 10'ar tohum olacak şekilde 5'er tekerrür (toplam 200 tohum) olarak kurulmuştur. Petri kapları içerisine yerleştirilen tohumlar üzerine 5'er ml sıvı pülverize edilmiş ve petri kapları streç filmle sarılmıştır. Ardından $24 \pm 2{ }^{\circ} C^{\prime}$ de (Suchockas 2006) karanlık koşullarda inkübe edilmiştir. İnkübatör içerisinde 30 gün boyunca muhafaza edilen tohumların haftalık olarak çimlenme durumları kontrol edilmiştir. Bu gözlem süresi boyunca tohumlara ayrıca su verilmemiştir.

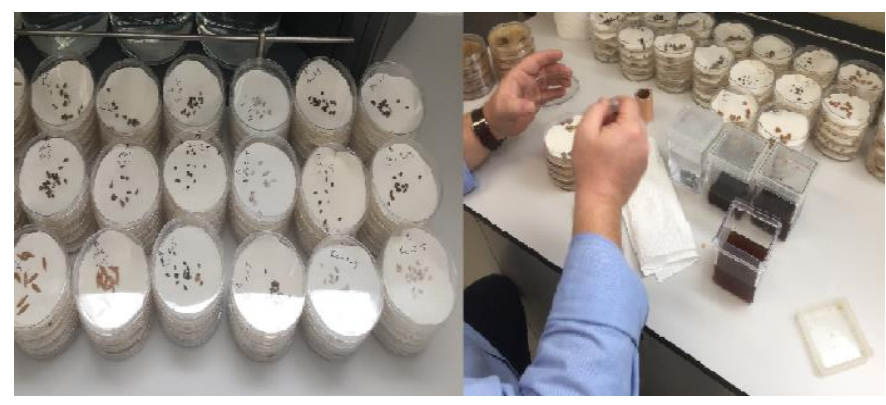

Şekil 2. Vermikompost çayının tohumlar üzerine uygulanması

\section{Verilerin analizi}

Çalışmada denemelerin tamamı "Tesadüf Parselleri Deneme Deseni"ne göre kurulmuştur.

Çimlendirme çalışmasında her bir türe ait tohumlar (karaçam, sarıçam, yalancı akasya, akçaağaç, sincan çalısı ve kapari) üzerine solucan gübresinin $1: 1,1: 2$ ve 1:4 oranında sulandırılmış farklı dozları ile birlikte kontrol grubu da denenmiştir. Çalışmada 6 çeşit bitki tohumu $\times 4$ doz uygulaması $\times 5$ tekerrür $\times 10^{\prime}$ ar adet tohum ile toplamda en az 1200 tohum, 120 adet petri kabına ekilmiştir.
Çimlendirme denemelerinden elde edilen veriler yinelemelerin ortalaması olarak varyans analizi yöntemi (ANOVA) ile GraphsPadPrisim Paket Programı ile Tukey testine göre kontrol edilmiştir $(P \leq 0.05)$.

\section{BULGULAR}

Çalışma kapsamında tohumların çimlendirilmesi amacıyla yapılan uygulamada, vermikompost süzüntülerinin tohumların çimlenmesini teşvik edici etkisinin olduğu gözlenmiştir (Tablo 1). Tohumların endospermlerinin ortamdaki suyu bünyelerine alarak tohum kabuklarının çatlattıkları ve sürgün meydana getirdikleri görülmüştür (Şekil 3).

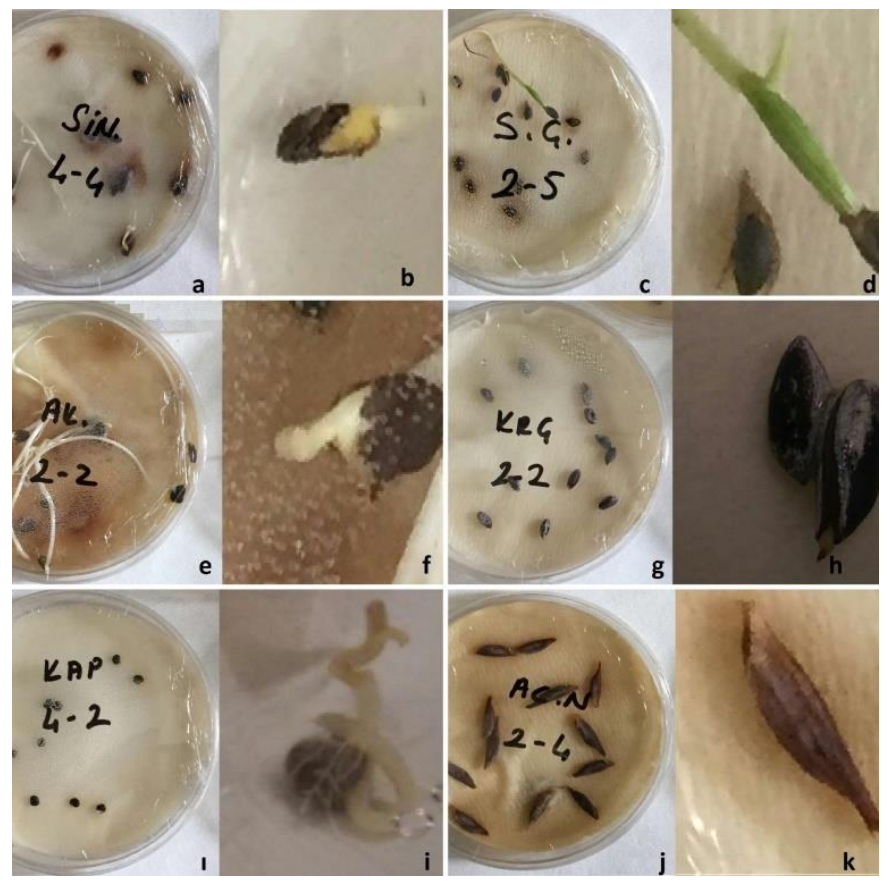

Şekil 3. Vemikompost çayı uygulaması sonucu tohumlardaki çimlenme. a-b) L. europaeum L.'da çimlenme c-d) P. sylvestris L.'da çimlenme e-f) $R$. pseudoacacia L.'da çimlenme g-h) P. nigra J.F. Arnold'da çimlenme I-i) C. spinosa L.'da çimlenme j-k) A. negundo L.'da çimlenme.

Tablo 1. Vermikompost çayı farklı doz uygulamalarının çimlenme üzerine etkisi $(P \leq 0.05)$.

\begin{tabular}{|c|c|c|c|c|c|c|}
\hline & Uygulamalar & Kontrol (0) & 1.Doz (1:1) & 2.Doz (1:2) & 3.Doz (1:4) & \\
\hline \multirow{6}{*}{ 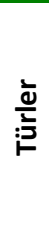 } & R. pseudoacacia & $0.26 \pm 0.046 c^{*}$ & $0.76 \pm 0.046 a$ & $0.48 \pm 0.095 a b c$ & $0.40 \pm 0.089 a b$ & $F=6.672 P=0.0039$ \\
\hline & P. nigra & $0.26 \pm 0.022 b$ & $0.10 \pm 0.040 \mathrm{~b}$ & $0.74 \pm 0.060 \mathrm{a}$ & $0.16 \pm 0.054 b$ & $F=31.35 P<0.0001$ \\
\hline & P. sylvestris & $0.14 \pm 0.045 \mathrm{~b}$ & $0.16 \pm 0.067 b$ & $0.62 \pm 0.059 a$ & $0.20 \pm 0.057 \mathrm{~b}$ & $F=12.53 P=0.0002$ \\
\hline & A. negundo & $0.04 \pm 0.036 \mathrm{~b}$ & $0.04 \pm 0.022 b$ & $0.68 \pm 0.052 a$ & $0.10 \pm 0.049 \mathrm{~b}$ & $F=45.07 P<0.0001$ \\
\hline & C. spinosa & $0.14 \pm 0.046 \mathrm{~b}$ & $0.06 \pm 0.022 \mathrm{~b}$ & $0.12 \pm 0.043 b$ & $0.64 \pm 0.046 a$ & $F=35.25 P<0.0001$ \\
\hline & L. europaeum & $0.13 \pm 0.054 \mathrm{~b}$ & $0.16 \pm 0.022 b$ & $0.10 \pm 0.040 \mathrm{~b}$ & $0.74 \pm 0.036 a$ & $F=52.29 P<0.0001$ \\
\hline
\end{tabular}

*Farklı harfler uygulamalar arası farklılıkları göstermektedir.

Tohumların çimlenmesi amacıyla toplamda 30 gün boyunca uygulanan inkübasyon sonucunda, tohumların ortamdaki suyu endosperm içerisine alarak şişmeye başladıkları ve teslanın çatlayarak çimlenmenin ilk evresini başlattığı görülmüştür. Tohum kabuğunun çatlayarak sürgün oluşumunu başlatması ile 
vermikompost çayının tohumların çimlenmesi üzerine pozitif etkileri ortaya çıkmıştır. Elde edilen veriler istatistiksel olarak değerlendirildiğinde; $R$. pseudoacacia L. tohumları üzerine yapılan uygulamada vermikompost çayının 1:1 oranındaki dozu çimlenmeyi (\%76) en çok teşvik eden miktar olduğu ortaya çıkmıştır. P. nigra J.F. Arnold (\%74), P. sylvestris L. (\%62) ve A. negundo L.'da (\%68) ise 1:2 oranında su ile seyreltilmiş olan vermikompost çayının tohumlar üzerinde çimlenmeyi artırıcı bir etki gösterdiği istatistiksel anlamda ortaya konulmuştur. Çalı formundaki $C$. spinosa L. (\%64) ile $L$. europaeum L. (\%74) tohumlarında ise 1:3 oranında seyreltilerek uygulanan vermikompost çayı tohumlar üzerinde çimlenmeyi artıran bir etki göstermiştir.

\section{SONUÇ ve ÖNERILER}

Yürütülen çalışma kapsamında; $R$. pseudoacacia L., $P$. nigra J. F. Arnold, P. sylvestris L., A. negundo L. ve çalı formundaki $C$. spinosa $L$. ile $L$. europaeum $L$. tohumlarında çimlenme potansiyellerinin artırılmasında kullanılabilecek vermikompostun (solucan gübresi) etkileri araştırılmıştır. Kontrol grubunun yanı sıra 1:1, 1:2 ve 1:4 oranında sulandırılarak seyreltik hale getirilen vermikompost süzüntüsü tohumlar üzerine $5^{\prime} \mathrm{er} \mathrm{mL}$ olarak uygulanmış ve $24 \pm 2^{\circ} C^{\prime}$ de inkübe edilmiştir.

Tohumların çimlenme oranları en yüksek \%76 en düşük \%62 olarak belirlenmiştir ki bu oranlar oldukça yüksek ve başarılı sayılabilecek bir oranlardır. Tohumların çimlendirilmesi amacıyla yapılmış birçok çalışmada farklı çimlenme oranları elde edilmiştir. Sarıçamda \%43-82 (Ertekin 2012), kaparide \%61.1 (Ulukapı ve Atmaca) ve \%74 (Söyler ve Aslan 2003), yalancı akasyada \%94 (Başbağ ve Ayzit 2010), karaçamda \%63.5 (Çılgın vd. 2007) ve \%54 (Çalışkan vd. 2014), akçaağaçta \%73 (Erkmen 2009) çimlenme oranları elde edilmiştir. Bu oranların bazıları çalışmada elde ettiğimiz çimlenme oranlarından yüksektir ve neredeyse hepsinde çimlenme engelini ortadan kaldıracak klasik yöntemler uygulanmıştır. Ancak, uygulamadaki kolaylık ve pratiklik açısından vermikompost çayı ile yapılan uygulama diğer yöntemlere göre basit ve zahmetsizdir.

Vermikompost çayı içerisinde organik materyalin (sığır gübresi, yiyecek artıkları vb.) bol miktarda bulunması bitki kökenli her türlü çalışmada kullanılabileceği anlamını taşımaktadır. Tamamen organik maddelerden elde edilen vermikompost, orman fidanlıklarında fidan üretimi çalışmalarında kullanılabilecek oldukça faydalı ve pratik bir materyal olarak karşımıza çıkmaktadır. Çalışmada gerçekleştirilen uygulamanın pratiğe dökülmesi oldukça basit ve düşük maliyetlidir. Orman fidanlıklarının neredeyse tamamına yakın bir kısmında vermikompost üretimi için gerekli materyal ve donanımın bulunuyor olması da bu yöntemin uygulanabilirliğini desteklemektedir. Üretilen vermikompostun tohumlar için uygun miktarda seyreltilmesinden sonra bir pülverizatör yardımıyla tohumlar üzerine püskürtülmesi tohumların çimlendirilmesinde ve fidan üretiminde daha başarılı sonuçlar elde edilmesine aracı olabilecektir.

\section{KAYNAKLAR}

Anşin R, Özkan Z (1997) Tohumlu bitkiler. Karadeniz Teknik Üniversitesi Orman Fakültesi Yayını No:167, Trabzon

Başbağ M, Ayzit D (2010) Yalancı akasya (Robinia pseudoacacia L.) ve gladiçya (Gleditsia triacanthos L.) tohumlarına uygulanan farklı sıcaklık derece ve sürelerinin çimlenme oranlarına etkisi. III. Ulusal Karadeniz Ormancılık Kongresi 20-22 Mayıs 2010 Cilt: II Sayfa: 759-765

Beck CB (2011). Bitki yapısı ve gelişimine giriş yirmibirinci yüzyılın bitki anatomisi. In: Demiray H (ed), Nobel Yay. No:227, Ankara

Buchanan MA, Russell E, Block SD (1988) Chemical characterization and nitrogen earthworms in environmental and waste management. In:Edwards CA ve Neuhauser EF (eds.), SPB Acad. Publ., the Netherlands, 231-239

Bürün B, Gürel A (2002) Embriyo kültürü. In:Babaoğlu M, Gürel E ve Özcan S (eds), Bitki biyoteknolojisi, Selçuk Üni. Vak. Yay. Konya, 324-344

Çalışkan A, Güney SH, Çalışkan S (2014) Farklı toprak işleme yöntemlerinin Anadolu Karaçamı (Pinus nigra Arnold subsp. pallasiana (Lamb.) Holmboe) gençleştirmesi üzerine etkisi. İstanbul Orman Fakültesi Dergisi, 64(2):56-68

Çılgın Ş, Ayan S, Sıvacıoğlu A, İktüeren Ş (2007) Hanönü (Kastamonu)Günlüburun Karaçam (Pinus nigra Arnold. subsp. pallasiana (Lamb.) Holmboe) tohum bahçesinde bazı klonların kozalak ve tohum özellikleri. Kastamonu Orman Fakültesi Dergisi, 7(2):169179

Doube BM, Brown GG (1998). Life in a complex community: functional interactions between earthworms, organic matter, microorganisms, and plants. In: Edwards C (ed) Earthworm Ecology, St Lucie Press, 179-211

Erkmen S (2009) Soğuk katlama ön işlemlerinin tatar akçaağacı (Acer tataricum L.) tohumlarının çimlenmesi üzerine etkileri. Ankara Üniversitesi Fen Bilimleri Enstitüsü Yüksek Lisans Tezi, Çankırı, $57 s$. 
Ertekin M (2012). Bbe sarıçamı (Pinus sylvestris L.ssp.hamata (Steven) Fomin var.compacta Tosun)'nın kozalak ve tohum özelliklerinde genetik çeşitlilik. Bartın Orman Fakültesi Dergisi, 14 (Özel Sayı):84-91

Gültekin CH (2014) Önemli orman ağaçlarının fidan üretim teknikleri (Kozalaklılar, Yapraklı ağaçlar) Orman ve Su İşleri Bakanlığı Orman Genel Müdürlüğü Kavak ve Hızlı Gelişen Orman Ağaçları Araş. Enstitüsü, Yayın No:26, i̇zmit

Gürpınar A (2008) Orman fidanı süs bitkisi yetiştiriciliği ve kalifiye orman iş̧̧iliği el kitabı. Ege Orman Vakfı Yayınları No:21

Logsdon G (1994) Worldwide progress in vermikomposting. Biocycle, 35(10):63-65

Patangray AJ (2014) Vermicompost: Beneficial tool for sustainable farming. Asian Journal of Multidisciplinary Studies, 2 (8): 254-257

Saday C (2013) Vermikültür üretimi, yaşanılan yasal zorluklar ve çözüm yolları ile üretim süreçleri ve gelişimi konusundaki deneyimlerinin aktarılması, In: Haktanır K (ed). TEMA Vakfı Ulusal Vermikültür Çalıştayı Bildiriler Kitabı, İstanbul, pp.20-36

Scheurell S, Mahaffee W (2002) Compost tea: Principles and prospects for plant disease control. Compost Science and Utilization, 10(4): 313-338

Söyler D, Aslan N (2003) Kebere (Capparis ovata Desf.) tohumlarının çimlenmesi üzerine farklı ön uygulamalar, sıcaklık ve ışıklanmanın etkileri. Tarım Bilimleri Dergisi, 10(2):127-132
Suchockas V (2006) Germination capacity of seeds and initial development of scots pine (Pinus sy/vestris L.) seedlings in various soil layers. Baltic Forestry, 12(2): 151-157

Şimsek Y (2007) Vermikompost ürünlerinin eldesi ve tarımsal üretimde kullanım alternatifleri. Gaziosmanpaşa Üniversitesi, Ziraat Fak Dergisi, 24(2); 99-107

Şimsek-Ersahin Y, Haktanır K, Yanar Y (2009) Vermicompost from agricultural wastes suppress Rhizoctonia solani Kuhn. in cucumber seedlings. J of Plant Dis and Pro, 116:182-188

Şimsek-Ersahin Y (2010) The use of vermicompost products to control plant diseases and pest, In: Karaca, A (ed) Soil Biology Biology Earthworms, Springer-Verlag, pp:191-213

Türkmen M (2016) Çevre odaklı üretim ve tarımsal girişimcilik bağlamında: vermikültür. J of Life Eco, 8:12-13

Ulukapı K, Atmaca S (2013) Türkiye'de doğal olarak yetişen Capparis spinosa L.'nın ın vitro ve ın vivo koşullarda çimlendirilme olanakları. Derim, 30(2):62-70

Ürgenç Si (1998) Ağaç ve süs bitkileri fidanlık ve yetiştirme tekniği. İstanbul Üniversitesi Orman Fakültesi Yayınları No:442, İstanbul

Yacubson D (1993) Orman ağacı tohumlarında çimlenme ve dormansi, In: Avşar M Forestry Canada Pacific Forestry Center, IUFRO, 149152 